\title{
O feminismo marxista se recria
}

Marxist Feminism Recreates Itself El feminismo marxista se recrea

Maria Ignez Silveira Paulilo' (iD 0000-0002-2437-2314

Universidade Federal de Santa Catarina, Programa de Pós-Graduação em Sociologia Política, Florianópolis, SC, Brasil.88040-900 - ppgsp.ufsc@gmail.com

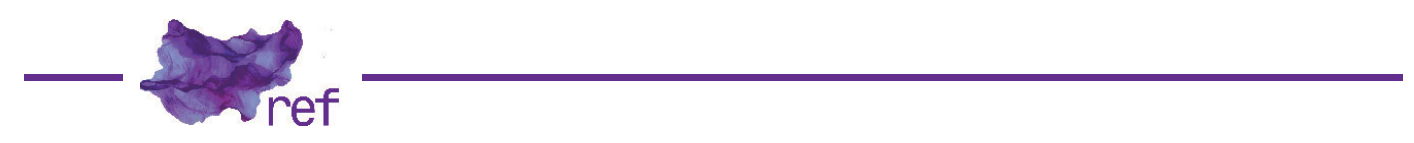

MEZADRI, Adriana; CIMA, Justina; TABORDA, Noeli; GASPARETO, Sirlei; COLLET, Zenaide (orgs).

Feminismo camponês e popular: reflexões a partir de experiências no Movimento de Mulheres Camponesas.

São Paulo: Outras Expressões, 2020. 189 p.

Essa é uma obra coletiva, contendo 13 artigos, escrita por 32 militantes do Movimento de Mulheres Camponesa (MMC). Tem por objetivo trazer elementos e concepções que foram construídos a partir da organização, formação e lutas do Movimento no Brasil. Suas vozes diferem da história oficial. Elas ousaram lutar contra o sistema capitalista, patriarcal e racista. Consideram-se um Movimento autônomo, feminista, camponês e socialista.

O livro conta a história do MMC que tem mais de 37 anos e tira as mulheres camponesas da invisibilidade; contempla as mulheres indígenas; se espelha nas ligas camponesas; confronta o racismo; enaltece as sementes crioulas e a segurança e soberania alimentares; exalta a alimentação saudável; critica a divisão sexual de trabalhos, o patriarcado e a violência contra as mulheres; torna visível a renda produzida pelas mulheres; fala da diversidade sexual; e finaliza com a importância da Mística para o Movimento. Sendo um livro didático, contém repetições.

"Em Movimentos de mulheres camponesas: veredas de muitas histórias", Carmen Lorenzoni, Iridiani Seibert e Zenaide Collet explicitam como as agricultoras construíram uma identidade camponesa, popular e feminista. Desde o início, 1983, o Movimento fez uma releitura latino-americana da Bíblia à luz da Teologia da Libertação e seguiu o método educacional de Paulo Freire, através de encontros. Em 1995, foi criada a Articulação Nacional de Mulheres Trabalhadoras Rurais - ANMTR. Em 2004, une-se à Via Campesina e se torna Movimento de Mulheres Camponesas - MMC. Às primeiras reivindicações trabalhistas vão incorporando questões de gênero até formarem o Feminismo Camponês e Popular.

Ana Munarini, Catiane Cinelli e Rosangela Cordeiro, em "A luta das mulheres camponesas: da invisibilidade para sujeitos de direito", mostram que foi importante para reconhecer 0 trabalho feminino considerarem as mulheres como "produtoras rurais" na Constituição de 1988, concedendo-lhes acesso aos direitos previdenciários. Outra conquista foi o Sistema Único de Saúde. A pressão dos movimentos populares expandiu os direitos à educação. Surgiu o Programa Nacional de Educação da Reforma Agrária e o Programa de Apoio às Licenciaturas em Educação do Campo. 
Edcleide Silva, Gabriela Santos, Glaciene Pereira e Margarida dos Santos, em "Mulheres indígenas: em defesa do território e da identidade", dizem que pensar nas indígenas é pensar em resistência de mais de quinhentos anos de um modo de viver coletivo, no qual tem grande importância a natureza e o território, sempre cobiçados pelos capitalistas. Em uma Primeira Marcha Nacional das Mulheres Indígenas, realizado em 2019, o lema foi "território: nosso corpo, nosso espírito". O MMC vem fazendo um trabalho de formação junto às indígenas e aprendendo com elas. Dos temas trabalhados em conjunto, o mais gritante é a violência contra as mulheres.

Edcleide Silva e Débora Santos, em "As ligas camponesas e a luta que marca os movimentos organizados no campo", relembram as Ligas Camponesas, porque são histórias e inspiram lutas atuais. Começaram na década de 1940, mas tiveram seu auge quando, em 1954, os foreiros do engenho Galileia, Pernambuco, se revoltam com o preço do foro. O advogado Francisco Julião de Paula passa a defender os agricultores. Em 1959 o engenho é desapropriado, o que reforça a luta das Ligas. Os trabalhadores sem terra começaram a se unir, mas a ditadura instalada em 1964 impôs dura repressão. O Movimento dos Trabalhadores Rurais Sem Terra se diz herdeiro das Ligas.

Itamara Almeida e Cleidineide Jesus, em "Feminismo camponês e popular: uma abordagem antirracista", dizem que a sociedade é racista. Prevalece a ideia de superioridade do branco ante negros e indígenas, justificando a superexploração de seu trabalho. O racismo é naturalizado. Segundo dados do Instituto de Pesquisa Aplicada - IPEA, em 2009, 12\% das mulheres brancas ocupadas eram empregadas domésticas contra $21,8 \%$ das negras. Segundo as autoras, o homicídio de mulheres não negras aumentou 4,5\% entre 2007 e 2017 , e o das negras, $29,5 \%$. O feminismo camponês e popular tem raízes afro-brasileira e indígena.

Clara Lima e Glaciene Pereira, em "Agricultura camponesa e agronegócio: mulheres em resistência", contrapõem essas duas formas de agricultura. Enquanto a primeira defende a agroecologia como ciência e modo de vida, produz alimentos saudáveis, preserva o solo e zela por todos os seres vivos, o agronegócio é uma atividade predatória, expulsa os camponeses e produz commodities, transformando água e terra em mercadoria e considera matas e animais silvestres como empecilhos. É excludente e produtivista, faz uso intensivo de agrotóxicos e sementes híbridas e transgênicas. A defesa da agroecologia é feita principalmente pelas mulheres.

Edcleide Silva e Ana Rauber, em "Sementes de resistência: caminhos para a produção de alimentos saudáveis", dizem que o MMC defende, junto com a Via Campesina, a Campanha Nacional Sementes de Resistência, com o lema Camponesas semeando esperança, tecendo transformação. No Fórum Social Mundial de 2003 foi lançada a Campanha mundial Sementes patrimônio da humanidade a serviço dos povos, para o perigo de transgênicos, agrotóxicos e monocultivos de pinus e eucalipto. Contra os monocultivos, as mulheres camponesas invadiram o Laboratório da Aracruz Celulose em 2006. Seus quintais produtivos são verdadeiros laboratórios experimentais informais.

Maria Cavalcanti, Maria Lucivanda da Silva e Noemi Krefta escreveram "Alimentação saudável: somos o que comemos". Uma das autoras, Maria Cavalcanti, lembra da infância o "alimento de pobre", catado no mato (CAVALCANTI; SILVA; KREFTA, 2020, p. 111). O monocultivo da cana chegava à porta dos moradores, não se podia plantar. Quando as usinas fecharam, tiveram que migrar. Só a ousadia do povo lhes permitiu criar movimentos como o $\mathrm{MMC}$, que, em 2001, iniciou campanha nacional de sementes crioulas. Em 2007, lançou a campanha nacional de produção de alimentos saudáveis, que traz de volta o alimento de pobre. Lançados pelo governo, os Programa Nacional de Alimentação Escolar - PNAE (2009) e o Programa de Aquisição de Alimentos (2003) - PAA, que compram alimentos orgânicos, incentivou as mulheres.

Isaura Conte, Michela Calaça e Noeli Taborda, em "Divisão sexual do Trabalho", falam da hierarquização de trabalho sexual. Considera-se que os homens fazem o trabalho produtivo, que gera renda, e as mulheres, o trabalho doméstico como algo natural. Mesmo quando geram renda, são desvalorizados. Dizer que o homem faz o trabalho pesado e a mulher o leve não se sustenta. O trabalho é leve porque a mulher o faz e não o contrário. O que é leve em uma região é pesado em outra, dependendo de quem o faz. Pesquisa realizada em 2006 por curso de extensão do MMC, mostram que o trabalho feminino, comparado aos preços mercado, geram mais de cinco salários-mínimos por pessoa ao ano, frente aos $0,5 \%$ do Salário Mínimo gasto em dinheiro. Rompe-se a dicotomia produtivo/reprodutivo.

Elisiane Jahn, Geneci Santos e Sandra Rodrigues, em "Economia feminista e as mulheres camponesas", mostram o quanto vale o trabalho mal ou não remunerado das mulheres. Pesquisa feita por Sandra Rodrigues em Foz do Iguaçu/PR examina 3 casos. No caso de Hortência, ela gastaria no mercado R\$3.357,61, mas só gastou R\$397,00. Catlleya gastaria no mercado R\$ 2851,90 , mas gostou R\$ 886,90 . Flor-de-Liz gastaria R\$ $1.174,62$, mas gastou R\$ 360,50 . Para as diferenças encontradas, as autoras denominam "economia feminista camponesa" (JAHN; SANTOS; RODRIGUES, 2020, p. 142).

Carmen Lorenzoni, Sandra Rodrigues e Sirlei Santos, em "Enfrentamento à violência contra a mulher", dizem que esta é um dos pilares do patriarcado. Há vários tipos de violência: física, sexual, psicológica e patrimonial. Mencionam ainda a violência do agronegócio que polui 
águas, ar e alimentos. O Brasil, segundo a ONU, em 2016 ocupava a 5a posição no ranking mundial de feminicídios. O MMC tem formulado cartilhas para alertar as camponesas sobre seus direitos. O Estado implantou a Lei Maria da Penha, que pune com mais rigor as agressões criou a Central de atendimento à mulher, "Ligue 180", para denúncias.

Angélica Cunha e Crísea Cristo, em "Diversidade sexual e heterossexualidade: contribuições para o feminismo camponês e popular", afirmam que a sexualidade humana é uma construção histórico-social e não biológica, reforçada pela sociedade patriarcal e capitalista. As outras formas de sexualidade são consideradas "desviantes" (CUNHA; CRISTO, 2020, p. 162), por isso vítimas de preconceito e LGBTfobia. A existência de lésbicas é considerada um ataque ao direito masculino de acesso às mulheres. O feminismo lésbico traz importante contribuição na medida em que nega que as mulheres são parte da propriedade emocional e sexual dos homens.

Adriana Mezadri, Justina Cima, Sirlei Gaspareto e Vanderléia Pulga, em "A mística feminina camponesa e popular no MMC", dizem que a palavra grega mística significa a busca para entender o que está escondido nas coisas. No MMC, ela é uma mística revolucionária que aponta para o sentido da existência humana, política, social, cultural e ambiental imbricada na vida das mulheres enquanto produtoras de alimento em harmonia com a natureza. Alimenta-se de muitas fontes: política, religião, estética/ética da vida, pedagogia libertadora, economia camponesa e feminista, inspirando-se na Igreja fundamentada na Teologia da Libertação. A mística celebra e cultiva um projeto político popular, através de símbolos, cultura, memória e sonhos.

Este livro é um marco na história recente do feminismo brasileiro, embora não conste de nenhuma coletânea atual sobre o tema. Daí a importância da resenha.

\section{Referências}

CAVALCANTI, Maria; SILVA, Maria Lucivanda da; KREFTA, Noemi. "Alimentação saudável: somos o que comemos". In: MEZADRI, Adriana; CIMA, Justina; TABORDA, Noeli; GASPARETO, Sirlei; COLLET, Zenaide (orgs). Feminismo camponês e popular: reflexões a partir de experiências no Movimento de Mulheres Camponesas. São Paulo: Outras Expressões, 2020. p. 111-122.

CUNHA, Angélica; CRISTO, Crísea. "Diversidade sexual e heterossexualidade: contribuições para o feminismo camponês e popular". In: MEZADRI, Adriana; CIMA, Justina; TABORDA, Noeli; GASPARETO, Sirlei; COLLET, Zenaide (orgs). Feminismo camponês e popular: reflexões a partir de experiências no Movimento de Mulheres Camponesas. São Paulo: Outras Expressões, 2020. p. 159-169.

JAHN, Elisiane; SANTOS, Geneci; RODRIGUES, Sandra. "Economia feminista e as mulheres camponesas". In: MEZADRI, Adriana; CIMA, Justina; TABORDA, Noeli; GASPARETO, Sirlei; COLLET, Zenaide (orgs). Feminismo camponês e popular: reflexões a partir de experiências no Movimento de Mulheres Camponesas. São Paulo: Outras Expressões, 2020. p. 133-144.

MEZADRI, Adriana; CIMA, Justina; TABORDA, Noeli; GASPARETO, Sirlei; COLLET, Zenaide (orgs). Feminismo camponês e popular: reflexões a partir de experiências no Movimento de Mulheres Camponesas. São Paulo: Outras Expressões, 2020.

Maria Ignez Silveira Paulilo (ipaulilo@terra.com.br) é doutora em Antropologia Social pela Universidade Federal do Rio de Janeiro (1987) e Pós-doutora pela The London School Of Economics And Political Science (1997). Atualmente é professora titular da Universidade Federal de Santa Catarina. Tem experiência na área de Sociologia, com ênfase em Sociologia Rural, atuando principalmente nos seguintes temas: agricultura familiar, gênero, campesinato, feminismo e movimentos sociais rurais.

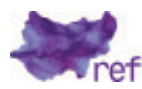


COMO CITAR ESTE ARTIGO DE ACORDO COM AS NORMAS DA REVISTA

PAULILO, Maria Ignez Silveira. "O feminismo marxista se recria". Revista Estudos Feministas, Florianópolis, v. 30, n. 1, e82136, 2022.

\section{CONTRIBUIÇĀO DE AUTORIA}

Não se aplica.

\section{FINANCIAMENTO}

Não se aplica.

\section{CONSENTIMENTO DE USO DE IMAGEM}

Não se aplica.

\section{APROVAÇĀO DE COMITÊ DE ÉTICA EM PESQUISA}

Não se aplica.

\section{CONFLITO DE INTERESSES}

Não se aplica.

\section{LICENÇA DE USO}

Este artigo está licenciado sob a Licença Creative Commons CC-BY 4.0 International. Com essa licença você pode compartilhar, adaptar, criar para qualquer fim, desde que atribua a autoria da obra.

\section{HISTÓRICO}

Recebida em 08/06/2021

Aceita em 24/08/2021 